\title{
The Politics of Anticipatory Expertise: Plurality and Contestation of Futures Knowledge in Governance - Introduction to the Special Issue ${ }^{1}$
}

\author{
Stefan C. Aykut \\ Universität Hamburg, Faculty WISO, Germany/stefan.aykut@uni-hamburg.de \\ David Demortain \\ INRA, Laboratoire Interdisciplinaire Sciences Innovations Sociétés (LISIS), France \\ Bilel Benbouzid \\ UPEM, Laboratoire Interdisciplinaire Sciences Innovations Sociétés (LISIS), France
}

The future is, as Arjun Appadurai (2013) puts it, a "cultural fact". Anticipatory practices - prophecies, utopias, predictions, forecasts, or scenarios - fulfil important societal functions in pre-modern and modern societies alike (Mannheim, 1991; Koselleck, 1985). They provide orientation in social interactions (Luhmann, 1997), shape expectations in market transactions (Merton, 1948; Beckert, 2013) and technology development (Borup et al., 2006), and constitute key resources for social organisation (Krämer and Wenzel, 2018) and political power (Scott, 1998; Mitchell, 2006; Ezrahi, 2012). Since World War II, such practices have undergone a process of scientisation and professionalisation. Formalised approaches draw on cybernetics, cognitive and behavioural sciences, gaming and econometrics, as well as techniques of computational modelling and simulation. They were forged in Cold War think tanks such as the US RAND Corporation (Andersson, 2012) and the International Institute for Applied Systems Analysis (IIASA) in Laxenburg, Austria (Rindzevičiūtè, 2016), as well as in Soviet, Dutch and French plan- ning circles (Desrosières, 1999; Andersson and Rindzevičiūtè, 2015). New impetus for the development of such techniques came in the 1970s, as growing concerns about industrial, environmental, and health risks prompted policymakers and governance bodies to evaluate the long-term consequences of their decisions (Buttel et al., 1990; Dahan, 2007; Seefried, 2015). Anticipatory knowledge practices turn 'the future' into an object of scientific enquiry and political intervention, hence giving shape to novel forms of "anticipatory governance" (Guston, 2014; Anderson, 2010). By producing information about what has not yet happened (and may indeed never happen), they reduce social complexity and constitute problems for acting in the present (Mallard and Lakoff, 2011). In doing so, however, they also reduce the inherent openness of the future, and risk closing down the "horizon of the possible for social and political creation" (Schulz, 2015: 132).

In sum, anticipatory expertise has become an indispensable core ingredient of contemporary attempts to govern complex problems and 
exhibits features of an institutionalised regulatory science (Demortain, 2017). These include the standardisation of dominant knowledge practices and the emergence of professional cadres of experts forming a part of, or entertaining close ties to, the state apparatus. At the same time, it has also become a field of contention, wherein a variety of technologies of knowledge production, social groups, and visions of the future coexist and compete. Indeed, the production of predictions and forecasts for public policy is not only an epistemic endeavour, but also an intrinsically contested and political activity. Its internal diversity - most policy environments count a variety of available technologies for producing anticipatory expertise - tends to reflect the politics and power contests of the corresponding worlds of policy formulation and implementation. As a result, the landscape of anticipation-for-policy is rapidly evolving. Profound changes affect the production and validation of knowledge, as well as its use in policy environments. The diversity of actors, sites and knowledge practices involved in anticipatory expertise is increasing.

Hence, while the study of anticipatory knowledge practices is hardly a new theme in science and technology studies, we see the need to take stock of these new developments. We also believe that such an endeavour necessitates to extend the scope of existing STS research. Previous studies have mostly concentrated on isolated and/or dominant knowledge practices, without paying much attention to the dynamic interplay or competition between different forms of anticipatory knowledge and their relation to the policy process. The special issue therefore builds on ongoing scholarly discussions about anticipatory knowledge and its 'performativity', to take a fresh look at the politics of anticipatory expertise. It also goes beyond the political science literature, which has investigated the role of forecasts and predictions in the political struggles and framing contests that accompany policy formulation (e.g. Baumgartner and Midttun, 1987; Grunwald, 2009), while showing only limited interest in unpacking the social dynamics underlying model construction, or the validation practices that found the credibility claims of anticipatory knowledge. Various new developments in the interstitial space between these two, scarcely intersecting strands of literature thus remain unattended, which this introduction and the contributions comprising the special issue offer to identify and explore.

\section{The performativity agenda}

Scholars have thoroughly investigated how the growing reliance on model-based simulations and predictions has reshaped entire scientific disciplines (Morgan and Morrison, 1999) and fields of technological innovation (Van Lente and Rip, 1998). A highly influential way to capture this rise of anticipatory practices has been through the notion of performativity in economic sociology (Callon, 1998; Mackenzie, 2004). Following Mackenzie (2006: 250), a broad, generic sense of the notion simply points to the fact that numerical models and other artefacts created by economists are taken up in economic practice. In a stronger sense, they materially 'equip' economic transactions and 'format' the ways in which such markets function. To be performative, future knowledge travels through socio-technical "arrangements of prediction" (Schubert, 2015) - instruments, infrastructure, and shared practices - which bring together social actors and redefine their preferences. The performativity argument has be extended to the making of economic policy. Braun (2014: 51) argues that models are key ingredients of "governability paradigms", which stabilise "when a sufficiently large part of the macroeconomic discipline is in agreement over the causal relationships between instrument and target variables, as well as over the way in which the former should be used by policymakers." Macroeconomic models have also been found to play key roles in policy change (Henriksen, 2013; Angeletti, 2011): as new models come to be embedded in policy circles and administrative practice, they contribute to wider transformations in the ways in which problems are identified and discussed, and solutions designed and implemented.

Other policy domains and model-based sciences are similarly concerned by these developments. In an early study on IIASA's first global energy forecast, (Wynne, 1984: 277) argues that this predictive exercise was highly consequential for policy formulation, as it delimited "what 
policies are even conceivable". The complex formalism of the underlying energy model tacitly embeds, and thereby reproduces, the worldviews and normative assumptions of its architects, imbuing them with an aura of scientific objectivity. Similarly, climate change forecasts simultaneously define through which mechanisms climate risks occur, what and who is at risk, and which adaptation policies might be appropriate (Jasanoff, 2010). Kieken (2004) goes one step further in a study on integrated assessment models (IAMs) - a type of model widely used in climate policy assessments. He holds that it would be wrong to depict IAMs as primarily scientific objects. Much to the contrary, exerting political influence is a constitutive goal of the IAM community and a fundamental ambition of IAM modellers (see also Cointe et al., in this issue). Following on this, Beck and Mahony (2017) show that the projections produced by such models even bring into being new political objects - such as 'negative emission technologies' - and argue that the resulting "politics of anticipation" pose challenges to common conceptions of scientific neutrality.

Another way in which models 'perform' is by coordinating the various social worlds implicated in policymaking. Models and their productions function as boundary objects that structure collaboration between academic communities (Edwards, 2010), and between experts and politicians (van der Sluijs et al., 1998; van Egmond and Zeiss, 2010). The MARKAL energy model, for instance, has been found "to perform different roles for different groups", a capacity which "has served to embed and institutionalise the model in the energy policy community" (Taylor et al., 2014: 32). While this has assured the model a rare longevity in administrative practice, over the years its technological focus has also reinforced an existing bias toward technical solutions in energy and climate policy. Modelling of environmental hazards is another case in point. It is practiced by specialised consultants who have established privileged relationships with policy managers. In a study on flooding risks, Catharina Landström and colleagues show that even though modelling practices are rarely subject to academic peer review, modellers tacitly "define what society needs to know about flooding in order to undertake risk management that is considered satisfactory" (Landström et al., 2011: 18,19).

\section{Pluralizing performativity}

The emergence of complex, socio-material "machineries" of anticipation (Nelson et al., 2008: 549) has wide-ranging consequences for policymaking. As it confers political influence to the expert communities that control the 'means of anticipation' - so to speak - the literature has also embraced normative considerations. Modelbased forecasts have been criticised for depoliticising policymaking and public debate (Voß, 2013), silencing the voices of lay publics and local populations (Miller, 2004; Mahajan, 2008) and restricting the expression of alternative imaginaries of the future (Jasanoff, 2010). When technoscientific or catastrophic future visions "colonise" or "abduct" the present (Adams et al., 2009: 255; Kaiser, 2015), they contribute to processes of "defuturisation" (Luhmann, 1990). This raises important questions pertaining to the accountability of modellers, and to possible ways of 'democratising' anticipatory expertise by associating wider publics in modelling or scenario building. It also points to the need to gain a better understanding of the diversity of ways of forging futures in policy the variety of actors involved.

No longer the monopoly of a few academic or state institutions, quantified future visions are produced within broader networks spanning public agencies and global governance bodies, scientific institutes and think tanks, as well as firms and civil society organisations (Voß et al., 2006; Guston, 2014). Policy intermediaries and knowledge brokers invest in anticipatory practices to sustain their role in changing policy environments, while transnational organisations and governance bodies play key roles in processes of model evaluation, validation and standardisation. Anticipatory knowledge production hence spans a variety of institutional loci at local, national and transnational scales. This geographic and spatial diversity in turn imposes differentiated requirements on the design and scope of model architectures. In addition, sharp increases in computing power and data availability have renewed existing knowledge practices, and led to the emergence 
of new ones. Classical quantitative models based on the law of large numbers and the associated notions of norms and means (Desrosières, 2000) now compete with machine-learning based techniques in which the model is no longer an input into the calculation, but an output (Cardon, 2015), as they proceed by testing all possible correlations between an ever-increasing number of features. As a result, predictions, forecasts and scenarios in many policy domains now form "ecologies" or "assortments of futures" (Michael, 2017) among which policy actors, stakeholders and activist groups can choose and within which they must navigate. Moreover, as the diversity of actors, instruments and governance scales in policymaking increases, modelling techniques tend to vary in form and content depending on the political context of knowledge production, and on the demonstrations that those who use models and their outputs are interested in making.

By contrast, the theme of performativity has typically been applied to situations characterised either by the existence of one dominant knowledge practice, or by a privileged relationship between a producer of anticipatory expertise and a (political) centre of decision-making - often the state (e.g. Nelson et al., 2008). We therefore feel the need to enrich the focus on performativity through a political sociology lens, which pays closer attention to conflicts and power asymmetries in knowledge production, as well as normalisation and regulation activities by public agencies and private actors (Frickel and Moore, 2006; Bonneuil and Joly, 2013). The political sociology of anticipatory expertise that we defend approaches predictions, forecasts and scenarios as one of the many 'currencies' mobilised by competing actor groups seeking to bear on the governance of public problems. As with other forms of policy-relevant knowledge, the social dynamics of modelling fields therefore reflect the politics of policymaking, the variety of intentions and actors involved, the power struggles among them, and wider shifts in policy frames. How do performance contests, so to speak, play out? How do various forms of anticipatory expertise co-construct or exclude each other in policymaking and governance? Amongst a diversity of anticipatory instruments and knowledge practices, what explains the success of some techniques and the failure of others? And how do such epistemic conflicts shape knowledge production in the first place?

\section{The contributions to the special issue}

To develop a differentiated take on contemporary transformations affecting anticipatory expertise, the articles assembled here span a variety of governance scales (local, national, global), countries (the US and the European Union, France, Germany and Belize) and policy domains (energy, climate, agriculture and food policy, risk regulation, forest and water management, policing). They cover different forms of knowledge production, ranging from formalised and computational to non-formalised, lay practices of anticipation. The authors also approach their objects from different theoretical and methodological perspectives, combining STS approaches with ethnography, history, political science, and sociology, while using analytical frameworks as diverse as coproduction, performativity, and field theory. All papers study the dynamics of anticipatory expertise against the backdrop of evolution in the corresponding policy field, to better understand how such expertise becomes embedded in, and co-constitutes the governance of, complex and contested policy issues. As the following summaries cannot do justice to the empirical richness and analytical diversity of these studies, we invite the interested reader to take a closer look at the articles themselves.

Three contributions focus on forecasts and scenarios in energy, climate and agriculture governance. Stefan Aykut provides a historical study on German and French energy policy, which links evolutions in energy modelling to key moments of policy change. Energy policy is envisioned as a field populated by competing "predictive policy assemblages" made up of discourses, human agents, knowledge practices and material artefacts. Dynamics of model development therefore tend to reflect wider political struggles: in the post-war decades, energy models helped constitute 'energy policy' as an autonomous policy domain structured around a specific representa- 
tion of the energy system and of available policy options. This changed in the 1970s, when activist groups 'equipped' with new modelling techniques proposed alternative future-visions and political ontologies, which enabled new forms of political intervention. The article concludes by specifying a series of conditions under which changes in knowledge practices can be expected to contribute to wider policy change. Béatrice Cointe, Christophe Cassen and Alain Nadai examine how IAMs became over the past decades the main tool for producing emissions scenarios for the Intergovernmental Panel on Climate Change (IPCC). IAMs represent interactions among environmental, technological and human systems in a single integrated framework. The authors retrace the structuration of the modelling community around both a common normative commitment to produce 'policy-relevant' knowledge, and of a shared 'repertoire' of organisational techniques and knowledge infrastructures, such as the creation of a research consortium, common scenario databases, and model intercomparison projects. This, they argue, created a wider convergence of research practices and agendas among scientists involved in climate expertise. It also anchored this nascent modelling technique and the corresponding epistemic community in global climate governance. Lise Cornilleau's contribution shows that similar dynamics are at work in global agriculture and food security governance. Drawing on neo-institutionalist and Bourdieusian field theory, she examines the processes through which certain knowledge practices come to be considered as more legitimate than others in policy contexts. Empirically, the paper centres on the competition between two distinct modelling communities. It narrates how the architects of a new model-type attempted to gain a better position in global expertise by emulating central features of the dominant modelling approach. The study demonstrates that modellers act as 'institutional entrepreneurs', actively creating and maintaining structural homologies between fields of expertise and governance. Echoing Cointe et al.'s central argument, Cornilleau contends that dominant modellers strategically used intercomparison exercises to maintain the high ground in policy advice, by setting implicit standards for modelling techniques that suit the incumbent expert community.

Two articles look into the prediction and management of environmental resources. Antoine Dolez, Céline Granjou and Séverine Louvel investigate forest science and management in France. Anticipatory expertise in this domain does not form a monolithic whole, as well-established practices of knowing and governing forest development coexist alongside newer ones that emerged in the context of climate change debates. The authors identify three "micro-regimes of anticipation": the adaptation of forestry to future climates; the prediction of tree biology; and the monitoring of forests as indicators of climate change. This diversity, they contend, both reflects the impact of the "big future" of climate change on knowledge production, while also pointing to wider changes in forest management, as different expert communities tend to maintain privileged relations with policy actors. Mapping such regimes helps understand the evolution, interaction and hybridisation of knowledge practices, as well as the conflicting politics of environmental anticipation. Sophie Haines offers an ethnographic study of anticipatory water management in Belize. Alongside formalised predictions based on statistics and modelling, she foregrounds the ways in which scientists, practitioners and policymakers navigate water futures through relational "reckoning" work. Necessary to "mak[e] measures and measurement meaningful", such work rests on a scientific ambition to know and predict, and on artefacts like datasets, models, and maps. However, it is also embedded in a complex web of social relations, which are shaped by political and economic struggles, and are thus affective, situated, and experiential. Haines argues that the indeterminacies surrounding data and its interpretation, as well as the political use of predictions, frequently lead to frictions, disorientation, and discontent. This material, social, and emotional context shapes what she calls the "political lives of anticipation". Anticipatory governance, the article demonstrates, has as much to do with scientific knowledge, as with situated practices of coping with non-knowledge and uncertainty.

The three final papers consider predictive modelling in risk regulation and security interven- 
tions. Bilel Benbouzid focuses on a commercially successful software package for predicting crime, PredPol. He analyses the construction and dissemination of the PredPol algorithm against the backdrop of other predictive technologies that motivated and inspired its development: statistical systems for identifying crime 'hotspots', and algorithms used by geologists to predict earthquakes and seismic aftershocks. By opening the black box of PredPol's mathematical composition - partially, as the algorithm is not public - Benbouzid shows how it embeds specific normative assumptions and policy frames. PredPol aims to 'optimise' police work, which makes it compatible with neo-managerial cost reduction efforts. In addition, PredPol's way of predicting crime independently of any consideration of the underlying social dynamics obfuscates the social causes that drive criminal behaviour. Henri Boullier, David Demortain, and Maurice Zeeman zoom in on modelling practices at the U.S. Environmental Protection Agency (EPA). The EPA has in recent decades become the site of the formalisation of a new practice of chemical hazards' prediction, derived from the modelling of statistical relationships between chemical structures and their biological activity. This might seem surprising, as the agency operates in a highly constrained epistemic environment: legal frameworks combine with organisational cultures to define the kind of knowledge that is routinely used, and limit the ability to embrace other types of information. The study examines against this backdrop how the EPA succeeded in turning highly uncertain and experimental modelling techniques into credible regulatory knowledge. It also shows that while this so-called SAR technique has come to occupy a central position in chemical's regulation, it does not predetermine risk regulation. Instead, modelling articulates with other ways of establishing chemical risks, such as empirical experiments. Brice Laurent and François Thoreau further explore chemical hazards modelling, this time in the European context. They also find that modelling of structure-agency relations does not replace expert judgment. It requires large doses of human intervention, for instance to determine the chemical substance to be modelled in each new case, or to correct problems of over- or underfitting with external data through parameterisa- tions. It therefore constitutes more than a simple mechanical tool, and tends to resists standardisation. Laurent and Thoreau argue that this feature of chemical hazards' modelling does not easily fit with the ideal of "mechanical objectivity" (Porter, 1995) that structures the European Union's risk governance. They also highlight that model-based regulation of chemicals poses critical questions of transparency, as it institutes power asymmetries between model developers in private companies interested in avoiding public scrutiny of their knowledge practices, and experts in the regulatory agencies in charge of assessing the models.

\section{Unpacking the politics of anticipatory expertise}

Despite the plurality of objects and approaches, a series of common themes and insights emerges from the articles. First, model-based predictions form part of, and are embedded in, a larger set of anticipatory practices that inform contemporary policymaking. The papers show that anticipatory expertise cannot be reduced to quantified predictions, nor to a single epistemic culture. It comprises various knowledge practices, tools, and organisations. New modelling techniques are commonly related to, contested by, and constructed against other models and claims about the future. Instead of replacing established (lay or expert) practices of anticipation, they complement them by addressing new questions, or produce 'frictions' when they challenge socially entrenched practices of anticipation. They also require new forms of judgment and human intervention, to calibrate them, contextualise their knowledge claims, and interpret their results.

Second, anticipatory expertise intervenes in all phases of the policy process. Modellers are consistent actors in policymaking, not occasional advisers brought into the process upon request by policymakers. This is not to say that anticipatory knowledge determines policymaking. Neither on top nor "on tap" - to paraphrase Winston Churchill - for policymakers, anticipation experts actively participate in policy formulation. Their tools, judgements and simulations are among the information sources and framing devices that shape public debates and agenda setting. They 
are also routinely used in policy implementation, for instance to calibrate policy instruments or monitor the impact of political measures.

Third, anticipatory knowledge is produced within sociotechnical 'collectives' or 'assemblages'. Knowledge about the future is inherently uncertain and thus particularly exposed to critique. To become a relevant and lasting feature of policymaking, it needs to be validated according to collectively held norms of credibility, through processes involving governmental assessment bodies, global standardisation organisations, and intercomparison projects. It also relies on 'infrastructures of anticipation' - in Edward's (2010) sense of vast machines of technical artefacts, epistemic infrastructures and social institutions - within which models and their results are controlled, compared and interpreted. This in turn creates path dependences in terms of knowledge practices and expert communities. In most of the cases analysed in the special issue, the tools, practices, and organisations involved in collecting data, constructing models and validating them, and producing anticipatory expertise, all have long histories.

Fourth, fields of anticipatory expertise are driven by struggles for hegemony between different knowledge practices and their proponents. The dynamics of such competition shape the relations between expert collectives and produce hierarchies among them. On one extreme, we find 'open markets' for expertise, in which a wide variety of knowledge producers compete for public attention and contracts. Here, entry barriers tend to be low, and validation and standardisation processes collectively negotiated. In cases where the capacity to produce formalised, authoritative knowledge about the future is more unevenly distributed, the field of expertise can take an 'oligopolistic' structure, or, on the other extreme, be dominated by a (near-)hegemonic knowledge practice. ${ }^{2}$ In these cases, the diversity of knowledge about the future is channelled by a general drive toward the standardisation of knowledge production, as well as by the fact that anticipation is sustained by and embedded in material artefacts and technical infrastructures, which constitute potent entry barriers for potential newcomers. Existing sociotechnical infrastructures of anticipation restrict competition in futures and policy knowledge.

Fifth, the dynamics of knowledge production reflect central features of policymaking in a given domain. The papers in this special issue show that anticipatory expertise in risk regulation (toxicology), strategic planning (energy, climate), administrative management (forest, water policies) and security interventions (policing) takes very different forms, depending on the actor configurations and prevalent modes of policy intervention at play in public policy. This raises interesting questions as to the ways in which expert communities and anticipatory practices articulate with policymaking and governance, and in which predictions, forecasts, and scenarios come to be translated into policy-relevant knowledge that circulates outside expert communities to become an integral element of policymaking.

Lastly, field-specific relations between experts and policy actors structure knowledge production and uptake. Such "patterns of interaction" (Miller, 2001) enclose distinct ways of envisioning and organising the translation of scientific knowledge into policy-relevant expertise. In climate governance for instance, modelling communities are formally incorporated into a larger "governance apparatus" (Feldman, 2011) through the mediation of technical assessment bodies. In energy policy, modellers tend to merge with competing policy networks by establishing privileged relationships with specific policy actors. This contrasts with fields like predictive policing, where relations between knowledge producers and users are only weakly formalised and more fluid. Such cases tend to accommodate a greater variety of knowledge practices. As these examples show, intermediary organisations of assessment, comparison, and standardisation play a critical role in structuring and strengthening the science-policy link. Accordingly, such organisations constitute key sites in struggles over economic resources and political influence. Where they do not exist, knowledge users typically struggle to evaluate competing predictive techniques, as knowledge producers have little interest in disclosing their epistemic practices. 
Taken together, the papers in this special issue illustrate the productivity of a perspective that combines STS and political sociology to gain a finer-grained understanding of anticipatory expertise in public policy. Such an analytical angle, we contend, leads beyond visions of anticipatory governance either as a process in which 'enlightened' policymakers base their decisions on rational assessments of the long-term consequences of different policy options, or as a process in which modelling experts and their predictions indistinctly 'depoliticise' public debate and predetermine policymaking. As models, forecasts, and algorithms have become a common - and in many ways indispensable - feature of contemporary policy debates, we hope that this special issue will stimulate further research that jointly analyses the politics of anticipatory knowledge production and the multiple ways in which such knowledge informs, intervenes in, and contributes to shaping the governance of public problems. 


\section{References}

Adams V, Murphy M and Clarke AE (2009) Anticipation: Technoscience, life, affect, temporality. Subjectivity 28(1): 246-265.

Anderson B (2010) Security and the future: Anticipating the event of terror. Geoforum 41(2): 227-235.

Andersson J (2012) The Great Future Debate and the Struggle for the World. American Historical Review 117(5): 1411-1431.

Andersson J and Rindzevičiūtè E (2015) The Struggle for the Long Term in Transnational Science and Politics. Forging the Future. New York: Routledge.

Angeletti T (2011) Faire la réalité ou s'y faire ? La modélisation et les déplacements de la politique économique au tournant des années 1970. Politix 2011/3(95): 47-72.

Appadurai A (2013) The Future as Cultural Fact. Essays on the Global Condition. London, UK: Verso.

Baumgartner T and Midttun A (1987) The politics of energy forecasting. A comparative Study of Energy Forecasting in Western Europe and North America. Oxford: Clarendon Press.

Beck S and Mahony M (2017) The IPCC and the politics of anticipation. Nature Climate Change 7(5): 311-313.

Beckert J (2013) Imagined Futures. Fictional Expectations in the Economy. Theory and Society 42(3): 219-240.

Bonneuil C and Joly P-B (2013) Sciences, techniques et société. Paris: La Découverte.

Borup M, Brown N, Konrad K and Van Lente H (2006) The sociology of expectations in science and technology. Technology Analysis and Strategic Management 18(3/4): 285-298.

Braun B (2014) Why models matter: the making and unmaking of governability in macroeconomic discourse. Journal of critical globalisation studies 7: 48-79.

Buttel FH, Hawkins AP and Power AG (1990) From Limits to Growth to Global Change: Constraints and contradictions in the evolution of environmental science and ideology. Global Environmental Change 1: 57-66.

Callon M (1998) The Laws of the Markets. Oxford, UK: Oxford University Press.

Cardon D (2015) A quoi rêvent les algorithmes. Nos vies à l'heure des big data. Paris: Le Seuil.

Dahan A (2007) Les modèles du futur. Paris: La Découverte.

Demortain D (2017) Expertise, regulatory science and the evaluation of technology and risk: Introduction to the Special Issue. Minerva 55(2): 139-159.

Desrosières A (1999) La commission et l'équation: une comparaison des Plans français et néerlandais entre 1945 et 1980. Genèses 34: 28-52.

Desrosières A (2000) The Politics of Large Numbers: A History of Statistical Reasoning. Cambridge, MA: Harvard University Press.

Edwards PN (2010) A vast Machine. Computer Models, Climate Data, and the Politics of Global Warming. Cambridge, MA: The MIT Press.

Ezrahi Y (2012) Imagined Democracies: Necessary Political Fictions. Cambridge and New York: Cambridge University Press.

Feldman G (2011) Illuminating the apparatus: Steps toward a nonlocal ethnography of global governance. In: Shore C, Wright S and Però D (eds) Policy worlds: anthropology and the analysis of contemporary power. New York, Oxford: Berghahn Books, pp. 32-49.

Frickel S and Moore K (2006) The New Political Sociology of Science-Institutions, Networks and Power. Madison: The University of Wisconsin Press. 
Grunwald A (2009) Energiezukünfte vergleichen - aber wie? In: Möst D, Fichtner W and Grunwald A (eds) Energiesystemanalyse. Karlsruhe: Universitätsverlag Karlsruhe, pp. 33-47.

Guston DH (2014) Understanding 'anticipatory governance'. Social Studies of Science 44(2): 218-242.

Henriksen LF (2013) Economic models as devices of policy change: Policy paradigms, paradigm shift, and performativity. Regulation \& Governance 7(4): 481-495.

Jasanoff S (2010) A New Climate for Society. Theory, Culture \& Society 27: 233-253.

Kaiser M (2015) Über Folgen. Technische Zukunft und politische Gegenwart. Weilerswist-Metternich Velbrück Wissenschaft.

Kieken H (2004) RAINS: Modéliser les pollutions atmosphériques pour la négociation internationale. Revue d'histoire des sciences 57(2): 377-406.

Koselleck R (1985) Futures Past: On the Semantics of Historical Time. Cambridge, MA: MIT Press.

Krämer H and Wenzel M (eds) (2018) How Organizations Manage the Future: Theoretical Perspectives and Empirical Insights. Basel: Springer.

Landström C, Whatmore SJ and Lane SN (2011) Virtual engineering: computer simulation modelling for flood risk management in England. Science \& Technology Studies 24(2): 3-22.

Luhmann H-J (1997) Die Gesellschaft der Gesellschaft. Frankfurt am Main: Suhrkamp.

Luhmann N (1990) Die Zukunft kann nicht beginnen. Temporalstrukturen der modernen Gesellschaft. In: Sloterdijk P (ed) Vor der Jahrtausendwende: Berichte zur Lage der Zukunft. Frankfurt am Main: Suhrkamp, pp. 119-150.

Mackenzie D (2004) The Big, Bad Wolf and the Rational Market : Portfolio Insurance, the 1987 Crash and the Performativity of Economics. Economy and Society 33: 303-334.

Mackenzie D (2006) An Engine, Not a Camera. How Financial Models Shape Markets. Cambridge, MA: MIT Press.

Mahajan M (2008) Designing epidemics: models, policy-making, and global foreknowledge in India's AIDS epidemic. Science and Public Policy 35(8): 585-596.

Mallard G and Lakoff A (2011) How claims to know the future are used to understand the present. In: Camic C, Gross N and Lamont M (eds) Social Knowledge in the Making. Chicago: University of Chicago Press, pp. 339-378.

Mannheim K (1991) Ideology and utopia. London: Routledge.

Merton RK (1948) The Self-fulfilling Prophecy. The Antioch Review 8(2): 198-210.

Michael M (2017) Enacting Big Futures, Little Futures: Toward an ecology of futures. The Sociological Review 65(3): 509-524.

Miller CA (2001) Scientific Internationalism in American Foreign Policy: The Case of Meteorology (19471958). In: Miller CA and Edwards PN (eds) Changing the Atmosphere. Expert Knowledge and Environmental Governance. Cambridge, MA: MIT Press.

Miller CA (2004) Resisting Empire: Globalism, Relocalization, and the Politics of Knowledge. In: Long-Martello M and Jasanoff S (eds) The Patchwork Planet: Local and Global in Environmental Politics. Cambridge, MA: MIT Press.

Mitchell T (2006) Society, economy and the state effect. In: Sharma A and Gupta A (eds) The anthropology of the state: a reader. Malden, MA: Blackwell Publishing, pp. 169-186.

Morgan M and Morrison M (eds) (1999) Models as Mediators. Perspectives on Natural and Social Science. Cambridge, UK: Cambridge University Press. 
Nelson N, Geltzer A and Hilgartner S (2008) Introduction: the anticipatory state: making policy-relevant knowledge about the future. Science and Public Policy 35(8): 546-550.

Porter T (1995) Trust in Numbers: The Pursuit of Objectivity in Science and Public Life. Princeton, N.J: Princeton University Press.

Rindzevičiūtė E (2016) The power of systems. How policy sciences opened up the cold war world. Ithaca and London: Cornell University Press.

Schubert C (2015) Situating technological and societal futures. Pragmatist engagements with computer simulations and social dynamics. Technology in Society 40: 4-13.

Schulz MS (2015) Future moves: Forward-oriented studies of culture, society, and technology. Current Sociology Monograph 63(2): 129-139.

Scott JC (1998) Seeing like a state: How certain schemes to improve the human condition have failed. New Haven, CN: Yale University Press.

Seefried E (2015) Zukünfte. Aufstieg und Krise der Zukunftsforschung 1945-1980. Berlin: De Gruyter.

Taylor PG, Upham P, Mcdowall W and Christopherson D (2014) Energy model, boundary object and societal lens: 35 years of the MARKAL model in the UK. Energy Research \& Social Science 4: 32-41.

Van Der Sluijs J, Van Eijndhoven J, Shackley S and Wynne B (1998) Anchoring Devices in Science for Policy. The Case of Consensus around Climate Sensitivity. Social Studies of Science 28(2): 291-323.

Van Egmond S and Zeiss R (2010) Modeling for policy science-based models as performative boundary objects for Dutch policy making. Science Studies 23(1): 58-78.

Van Lente H and Rip A (1998) Expectations in Technological Developments: An Example of Prospective Structures to be Filled in by Agency. In: Disco C and Van Der Meulen B (eds) Getting New Technologies Together: Studies in Making Sociotechnical Order. Berlin: Walter de Gruyter, pp. 202-230.

Voß J-P (2013) Technikwissenschaftliches Wettrüsten für nachhaltige Entwicklung? Wo transformative Wissenschaft hinführen könnte. Ökologisches Wirtschaften 2013(2): 28-29.

Voß J-P, Bauknecht D and Kemp R (2006) Reflexive Governance for Sustainable Development. Cheltenham: Edward Elgar.

Wynne B (1984) The institutional context of science, models, and policy: the IIASA energy study. Policy Sciences 17(3): 277-320.

\section{Notes}

1 This special issue derives from the research project INNOX - Innovation in Expertise. Modeling and simulation as Tools of Governance, supported by the French Agence Nationale de la Recherche (Grant $n^{\circ}$ ANR-13-SOIN-0005), between 2014 and 2017. The majority of papers included in this special issue were presented at various workshops held during this project or at its concluding event "Governing by prediction? Models, data and algorithms in and for governance" held in Paris in September 2017 (innox. $\mathrm{fr}$ ). The three guest editors would like to thank the editors of the journal for supporting the publication of this special issue and the many colleagues who participated in the conversations that took place throughout the project and during the preparation of this special issue.

2 Hence, neoclassical economics has come to claim a quasi-“monopoly over the future" (Appadurai, 2013), partly through early investment in predictive techniques of computational modelling. 